Int. J. Electrochem. Sci., 11 (2016) $4943-4956$

\title{
3-(diethylamino)-1-phenylpropan-1-one as a Corrosion Inhibitor for N80 Steel in Acidization of Petroleum Exploitation
}

\author{
Hu Wang ${ }^{1,2}$, Yushuang Liu, Juan Xie ${ }^{1}$, Junlei Tang ${ }^{2,3, *}$, Ming Duan ${ }^{2,3, *}$, Yingying Wang ${ }^{3}$, \\ Mohamad Chamas ${ }^{3}$ \\ ${ }^{1}$ School of Materials Science and Engineering, Southweast Petroleum University, Chengdu 610500, \\ P.R.China \\ ${ }^{2}$ State key Laboratory of Oil and Gas Reservoir Geology and Exploitation, Southwest Petroleum \\ University, Chengdu 610500, P.R.China \\ ${ }^{3}$ School of Chemistry and Chemical Engineering, Southwest Petroleum University, Chengdu 610500, \\ P.R.China \\ *E-mail: junleitang@126.com
}

doi: $10.20964 / 2016.06 .74$

Received: 22 March 2016 / Accepted: 15 April 2016 / Published: 4 May 2016

\begin{abstract}
In this paper, the inhibiting performances of an acidizing corrosion inhibitor of 3-(diethylamino)-1phenylpropan-1-one (Mannich base, $\mathrm{MB}$ ) for $\mathrm{N} 80$ steel in $15 \% \mathrm{HCl}$ solution was investigated using electrochemical and weight loss measurements. Polarization curves showed that MB inhibitor is a mixed-type corrosion inhibitor, which inhibits both the anodic and cathodic process of corrosion reaction. In addition, an apparent passivation region can be observed at anodic curves in the presence of high concentrations of MB, indicating a stronger barrier film at the interface. EIS also showed different pattern in different concentrations. Two capacitive impedance loop and two time constants, occurred at high MB concentrations, indicates two electrochemical kinetic processes at the interface, corrosion electrochemical process and the inhibitor film. Weight loss results showed that the MB inhibitor is highly efficient at all test temperatures. Activation energy and free energy obtained by fitting of the weight loss data proved that the adsorption of MB inhibitor is a complex mixed type, both physisorption and chemisorptions. SEM further proved MB inhibitor is highly efficient in inhibiting corrosion of $\mathrm{N} 80$ in $\mathrm{HCl}$ solution.
\end{abstract}

Keywords: Corrosion inhibitor; Hydrochloride acid; N80 steel; Polarization; EIS

\section{$\underline{\text { FULL TEXT }}$}

(C) 2016 The Authors. Published by ESG (www.electrochemsci.org). This article is an open access article distributed under the terms and conditions of the Creative Commons Attribution license (http://creativecommons.org/licenses/by/4.0/). 